\section{Gambling in children and adolescents}

\author{
Rina Gupta, Jorge L Pinzon; Canadian Paediatric Society, Adolescent Health Committee
}

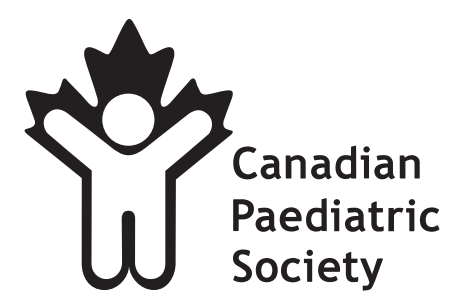

Full text at www.cps.ca Français en page 265

\begin{abstract}
Despite the fact that minors in Canada are prohibited from legalized gambling, adolescents commonly engage in both legalized (lottery products, casino, video lottery terminals) and self-organized (cards, sports betting, dice) gambling activities both at home and in school. Lifetime prevalence rates of pathological gambling for adults range from $1 \%$ to $2 \%$, and existing data suggest that the prevalence among adolescents may be two to four times higher. Very little is known about risk factors in the development and perpetuation of problematic and pathological gambling. This statement is intended to educate paediatricians, family physicians and other health care providers about the emerging knowledge around gambling in childhood and adolescence and the potential serious consequences of this activity. It also urges federal, provincial and territorial governments to include this specific issue in their agendas and to address the socio-political factors associated with gambling.
\end{abstract}

Key Words: Adolescent gambling; Pathologic gambling

\title{
RECOMMENDATIONS
}

Physicians and other health care providers should:

- Ask older children - especially adolescents - about gambling behaviours, especially when other known associated behaviours are present.

- Use known guidelines to screen for a gambling problem: frequency, tendency to gamble more than planned and behaviours suggesting they are hiding their gambling behaviour.

- Screen for depression and suicide risk in adolescents who are aware of their gambling problem, since they have likely incurred significant financial debt.

- Become familiar with local treatment providers and treatment services for problem gambling. Providers who treat substance abuse may be willing to work with youth who gamble excessively.

- Advocate for schools to become proactive regarding gambling among students by:

- Making teachers and school counsellors aware that gambling behaviour among youth entails risks, including school failure and absenteeism.

- Having school-based counsellors talk to teens about the risks of gambling when they are aware of substance use, because of the strong association between those two behaviours.

- Helping school boards to adopt and enforce a no-gambling policy within their schools.

Federal/provincial/territorial governments that run gambling programs should:

- Address the sociological and environmental impact of gambling on young Canadians (ie, exposure, accessibility and public attitudes), as well as the cost/benefit ratio of the current situation.

- Develop effective strategies to support youth and families afflicted by this public health phenomenon.

- Government and legislative bodies should assess, evaluate and control the potential impact of advertising on gambling initiation and maintenance on vulnerable populations, including children and youth.

- Provincial/territorial governments should assess the potential impact of new gambling offerings (for example, online gambling via lottery corporations) on youth before implementation, to ensure that the harm from such initiatives is minimized.

More research is needed to better understand this public health problem:

- Despite a growing body of cross-sectional research identifying risk factors associated with the development and perpetuation of problem gambling, large-scale longitudinal research projects are needed.

- A study on the overall economic, individual and social impact of legalized gambling on Canadian society is needed. Similar initiatives in other countries have proven beneficial.

- Federal, provincial and territorial governments should actively support such research endeavours with funds specifically allocated to the study of problem gambling in youth. 


\section{ADDITIONAL RESOURCES}

- International Centre for Youth Gambling Problems and High-Risk Behaviors <http://www.youthgambling.com>

- Canadian Centre on Substance Abuse, Gambling Statistics <http://www.ccsa.ca/Eng/Statistics/Canada/GS/Pages/default.aspx>

NOTE: For parent information visit www.caringforkids.cps.ca

ACKNOWLEDGEMENT: This position statement has been reviewed by the Canadian Paediatric Society's Mental Health and Developmental Disabilities Committee.

\section{ADOLESCENT HEALTH COMMITTEE}

Members: Franziska Baltzer MD; April S Elliot MD; Johanne Harvey MD; Margo A Lane MD; Stan Lipnowski MD (Board Representative); Jorge L Pinzon MD (Chair)

Liaison: Mark Norris MD, CPS Adolescent Health Section

Principal authors: Rina Gupta PhD; Jorge L Pinzon MD

The recommendations in this statement do not indicate an exclusive course of treatment or procedure to be followed. Variations, taking into account individual circumstances, may be appropriate. All Canadian Paediatric Society position statements and practice points are reviewed on a regular basis. Please consult the Position Statements section of the CPS website (www.cps.ca) for the full-text, current version. 